\title{
JOURNAL OF THE ROYAL SOCIETY OF MEDICINE
}

May 2007 Volume 100 Number 5 ISSN 0141-0768

\section{Connections with death}

'I am not afraid of death,' said Woody Allen, 'I just don't want to be there when it happens.' This issue of the JRSM has several connections with death, and even if the JRSM might not be there when it happens, it does find out about it eventually.

First, and most embarrassingly, I recently received the following email: 'Did you know that one of the Journal advisory board members died several years ago? He is Robert Volpe from Toronto. I do not know exactly when he died. His name is still listened [sic] in your Journal under the list of International members. I thought you would like to know.'

Hard on its heels, I learnt of the death of a contributor to this journal, Imre Loefler, whose final published work appears in this month's issue (pp. 248-250). True to form, Loefler eloquently challenges orthodoxy and our scruples with a piece arguing that cultural assimilation may be no bad thing for indigenous people. Loefler manages to entertain, appal, and confound in equal measure. He concludes: 'Keeping cultures alive, cultures that have failed the struggle for survival - even if this was the result of invasion-impoverishes the people representing that culture, it may perpetuate discrimination and it will prevent equity in education and medical care even in the face of a new wave of moral rearmament.'

Several readers, spurred on by moral indignation, tell us that the JRSM's report on the death of nursing - the title said 'demise' but it's near enough — was exaggerated. Robust responses appear in our letters pages (pp. 208210). 'A catchy title,' begins Bill Tucker, 'but I wasn't expecting the authors to show such astonishing lack of insight into the causes of this decline.' The authors, however, are undaunted (p. 210). This debate is alive not dead. 'It is nursing that is in demise,' restate Linda Shields and Roger Watson, 'and we have seen nothing in any responses to suggest otherwise. To ask for a retraction . . . is a ridiculous and unmeasured expectation and none will be forthcoming.'

Preferences about death are the subject of an overview of the UK policy context and the published literature by Daniel Munday and colleagues (pp. 211-215). They examine the issues that arise for health-care professionals in exploring with patients their preferred place of death, but warn of the dangers of insensitivity with the introduction of a financial incentive for practitioners to record a patient's preference (under the Quality and Outcomes Framework). The process must remain a sensitive one, they say, rather than becoming a "mechanical "tick box" exercise'.

Preferences and palliation are highly topical. While palliative care is often associated with cancer patients, there is now widespread recognition that other patients may be being denied care, such as people with end-stage chronic obstructive pulmonary disease and heart failure. David Seamark and his team provide a review on palliative care in chronic obstructive pulmonary disease (pp. 225-233). Based on data from 1999, 28000 deaths were from chronic obstructive pulmonary disease in the UK, around $5 \%$ of all deaths.

With an ageing population, exposed to the hazards of smoking, these numbers can only have increased over the last eight years and will continue to do so. Palliative care is a medical specialty that is becoming increasingly multidisciplinary and increasingly important as people search for a good death, a golden goal at the final whistle.

We should not then fear death, as Woody Allen suggests, but death comes in many forms to individuals, peoples, and professions. It is not to be feared but it does require somebody to tell a medical journal that it has happened.

\section{Kamran Abbasi}

Editor, JRSM

[Kamran.abbasi@rsm.ac.uk] 